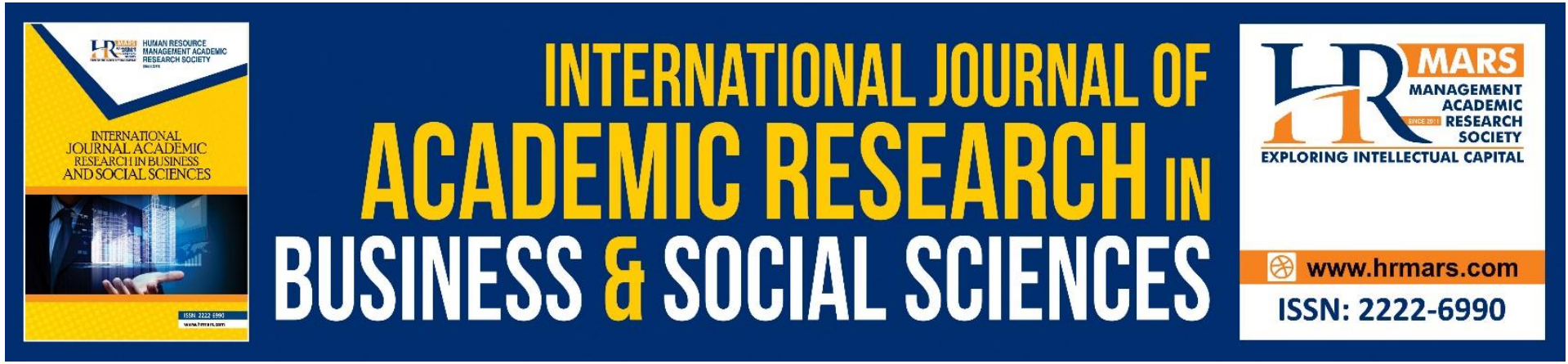

\title{
Depiction Heroic Animated Characters: Describing a Brief Process of Archetype Embodiment into a Genuine Nusantara -Inspired Content
}

Ahmad Azaini bin Abdul Manaf, Fythullah Hamzah, Azwan Abidin

To Link this Article: http://dx.doi.org/10.6007/IJARBSS/v11-i7/10241

DOI:10.6007/IJARBSS/v11-i7/10241

Received: 15 May 2021, Revised: 18 June 2021, Accepted: 24 June 2021

Published Online: 04 July 2021

In-Text Citation: (Manaf et al., 2021)

To Cite this Article: Manaf, A. A. bin A., Hamzah, F., \& Abidin, A. (2021). Depiction Heroic Animated Characters: Describing a Brief Process of Archetype Embodiment into a Genuine Nusantara -Inspired Content. International Journal of Academic Research in Business and Social Sciences, 11(7), 230-240.

Copyright: @ 2021 The Author(s)

Published by Human Resource Management Academic Research Society (www.hrmars.com)

This article is published under the Creative Commons Attribution (CC BY 4.0) license. Anyone may reproduce, distribute, translate and create derivative works of this article (for both commercial and non-commercial purposes), subject to full attribution to the original publication and authors. The full terms of this license may be seen

at: http://creativecommons.org/licences/by/4.0/legalcode

Vol. 11, No. 7, 2021, Pg. 230 - 240

Full Terms \& Conditions of access and use can be found at http://hrmars.com/index.php/pages/detail/publication-ethics 


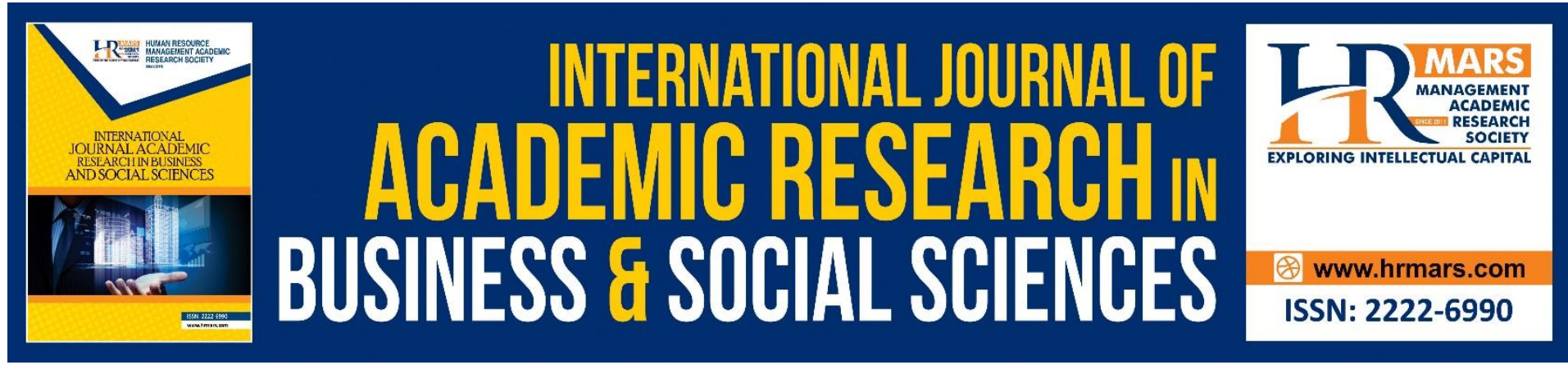

\title{
Depiction Heroic Animated Characters: Describing a Brief Process of Archetype Embodiment into a Genuine Nusantara -Inspired Content
}

\author{
Ahmad Azaini bin Abdul Manaf \\ Faculty of Applied and Creative Arts, Universiti Malaysia Sarawak, 94300 Kota Samarahan, \\ Sarawak \\ Email: azainimanaf@gmail.com
}

Fythullah Hamzah

Faculty of Applied and Creative Arts, Universiti Malaysia Sarawak, 94300 Kota Samarahan,

Sarawak

Email: kromosom@kromosomlab.com

\begin{abstract}
Azwan Abidin
Universiti Malaysia Sarawak Faculty of Applied and Creative Arts, Universiti Malaysia Sarawak, 94300 Kota Samarahan, Sarawak

Email: aazwan@unimas.my
\end{abstract}

\begin{abstract}
The importance of characters in in animation has received much attention in research on digital content industries, as well as an important tool for acting in animation content. This article highlighted the importance of archetypes and attributes in the Nusantara-based character design. This includes the review of current trends and envisages the weaknesses of character design in animated films, along with recommendations to improve character design's traits, parameter, silhouette, and suggested archetype. In conclusion, well-designed animated characters of Nusantara with strong resonance imply to increased audience satisfaction. Future research is recommended to elevate a good development of character design in contributing economic benefit for 600 million population in Southeast Asia in developing Nusantara digital content.
\end{abstract}

\section{Introduction}

Mythological Monsters and Fantasies: Nusantara folklore Stories

The Nusantara folklore stories dominate the southern part of Southeast Asian, composing 65 percent of its territory (Hamzah \& Manaf, 2020). Most of the successful characters of Southeast Asia are developed from myths, fantasies, lifestyles, and superheroes from storybooks or comics that are being visualized through the art of digital animation (Lent, 
2004). Uniquely, majority of the Nusantara region shared the common traits depicting a heavenly realm, legendary characters, mythological monsters, and epic storyline. In fact, character design, which is anchored through physical form and costume of cultural characteristics, plays a critical role in expressing personality and has become a backbone in animation content (Khalis \& Mustaffa, 2017). Hence, ideologically, the characteristics of Southeast Asian folklores are rooted in their collective local cultural and traditional beliefs, and the vibrancy of cultural content is deeply embedded with in dominance of character design.

In general, the attributes of a character are influenced strongly by histories, such as local traditional attire, ancient ornaments and weaponry to represent the character's stature. A believable animated character could also progress in accordance with the character personality, and thus the journey should also be narratively consistent throughout. As a consequence, poorly designed characters do not resonate emotionally with the audience would trigger detachment from their surroundings. This relates to the role of character designer, who is in charge of developing a character's overall concept, style, and artwork from early stages of the development phase. This entails conducting a detailed analysis of the character's personality to establish a visual note of the character's physical characteristics. In the reality of character design development and process, some factors such as comfort, body anatomy, technical challenges, and breathability have become aspects where designing differs between human characters from designer's view (Giri \& Stolterman, 2020). Such an activity reveals the fact that there are differences and similarities techniques in character designing to create a usable design within a specific pipeline. Thus, the aim of this paper attempts to highlight the design process specifically to obtain Nusantara characters that are both consistent and coherent to the international market.

\section{Weaknesses and Sciolism of Nusantara Narrative in Animation}

Nusantara is derived from the Malay word Nusa, which means islands and Antara, where it means across or in between. Bowring (2018) defines Nusantara, a Sanskrit word, then Malay, which refers to an island realm. Nusantara also known as 'Maritime Southeast Asia', is the world's largest archipelago and has been a vital cultural and trading hub for centuries. In the sense of culture, Nusantara narrative shares the core iconic element in its storytelling such as the kris (keris), headgear (tanjak), and sails (layar). The trinity index points to an identity carved in ancient temples and written in notable scriptures and should not be mistaken for other civilizations. The narrative of Southeast Asia can be divided into two major sections: northern and southern. In details, the northern section narrative usually revolved around Buddhism scriptures, whereas the latter narrative focused more on Nusantara content shared along the equatorial island belt. Thus, despite the diversity and broadness of Southern Asian content, the narrative nucleus can be found in the ancient Malay scriptures.

When it comes to animation content, western culture frequently portrays far eastern cultures as unique and full of potential, and it quite often experimented with similar narrative approaches. Recently, a film by Disney's Raya and The Last Dragon (Hall \& Estrada, 2021) has similarity of elements, where narrative showed that the eclecticism in character design and mixed-cultural representation. The content was praised for rollicking Southeast Asian-styled fantasy, but it ended up confusing the true Southeast Asian culture. The story's setting in fictional land of Kumandra, adds to the story's confused origins and uncertainty. Supposedly, 
the location and identity are generally implying to the Southeast Asian countries, as a strategic location reflects to the culture of Nusantara. However, the production house ignored the locality factor in culture-based identity and applied 'universal' roles for the non-white character. This implies a one-size-fits-all situation and raises the question, "one can't help but wonder why all these nations had to be thrown into a proverbial blender. Was it impossible to conceive of entire story set in Thailand or the Philippines?" (Coomes, 2021, para. 2). Clearly, it is critical to understand and prioritize the wide range of Nusantara customs and traditions in visual form. Besides, because they were sourced from a specific region, this can help to avoid mixing and matching the visual designs.

In the current century, animation content featured a broader range of foreign characters from a diversity of cultures. While the global audience started to grow, the reception has been varied, with some viewers were delighted and undelighted with the visuals. This means that authenticity and creative control are always at conflict, leading to exclusivity and monocultural approaches, as well as backward depictions of characters. At the same time, animated content illustrating Southeast Asian characters is aimed at Asian communities in Western countries, not those representing origins from the region. This approach led to a detachment of cultural believability and criticism among the target market audience. In most cases, integrating localized cultural consultants to address cultural appreciation leads to a better depiction of targeted issues in content development. However, in the end, producers are more probably to cherry-pick preferred culture and integrates into their show. In fact, the production studios did their best to fabricate cultural customs and beliefs in order to avoid unfamiliar design. These, as a whole, indicated that issues of nuanced representation have the ability to homogenize Southeast Asia's characters into a fictional chimera. The character design should broaden its scope to encompass more than individual differences in diversity. This entails synthesizing findings from contemporary research in cross-cultural aspects to inform the design and production of culturally based characters (Maldonado \& Hayes-Roth, 2004). In the same way, by doing in-depth observations within the domain of anthropology, they may discover reliable and unreliable elements of cultural components. Therefore, when dealing with cross-cultural issues in animation, it is possible to avoid being presumptuously ignorance (Abdullah \& Abdullah, 2020).

\section{Character Personality}

\section{An Overview of Current Design Process}

The goal of this study was to gain a better understanding of the process of Nusantara-based character design, as well as how visual attributes can be purposefully used to communicate character's personality. In character design, the 'who' and 'what' are both equally important. It is essential to combine the physical traits with the narrative to show the audience the character's background narrative. In animation, the value of character design can indirectly affect viewers' emotions (Arshad et al., 2018). And, in reality, emotion has always been affected by culture in a variety of ways (Lim, 2016). Thus, designing the character of different cultures is considered as an exercise that is rooted in characteristics of humanity, such as folklore and cultural beliefs (Ramos et al., 2016).

There are several industry pipeline applications available for creating characters for animated content. Although there is no specific formula, it is essential for designers to follow a specific step to complete the task within a particular time frame. Synchronously, this process allows 
producers and/or creative directors to make a significant contribution to the project. In fact, character designers use various methods to solve the same problem. Tons of ideas and sketches are produced during the process of exchanging information from a text-based information to a visualization medium. The depicting of such characters required of set of skills depict those characters attractively. In this sense, (Seegmiller, 2007) suggests creating a good character design assumes that work methods change depending on the situation and the artist.

More importantly, the character design process and documentation must be completed concurrently to ensure to give a better understanding. The author proposed a three-tier chronological in this article, which included research, concept, and rendering. Each stage focuses on what needs be produced for a specific aspect of the project. Therefore, a proposed working model constructed using the method discussed by Ekström (2013) and Lioi (2009) by segregating preparation and generative processes in order to achieve a smooth and seamless problem-solving design process.

\section{Nusantara-Inspired Characters Defining Character Creation Processes}

The parameters in a typical production exercise are the constraints that guide the design process. Everything that influences the appearance of the character must be considered a project parameter. A project brief or story synopsis can be used to obtain parameters. It seeks to establish the character design parameters, such as the story genre and target audience. The process of identifying and understanding problem that corresponds to the requirements of characters that designers must grasp to design it. Also, a character creation must occur within certain parameters to influence a specific audience according to a particular art style. It is crucial to generate three categories of project parameters: story constraints, animation requirements, and character briefing (Lioi, 2009). Thus, the designers must keep in mind that the real objective is to understand and work within the limitations.

\section{Visual and Textual Research}

Visual research and references are crucial to collect images that contain patterns, shapes, silhouettes, materials, constructs, pieces, anatomy references, and any other type of graphic recording of an element that can be used for an appropriate inspiration. At this point, the designer must identify the subject matter and research previous content that is similar to the the project briefing. Another technique is to create a mood board in order to define and discuss the project's direction with creative directors. A collection of samples showcasing of variation of design within the discussed subject matter will determine the project's visual compass.

\section{Concept}

Ideation

Ideation is the process of developing ideas and solutions through activities such as sketching and brainstorming. The goal for the creative team to generate a large number of ideas and offer the most practical design. In fact, ideation process will help to narrow down the requirements and provide design insight. In this stage, the designers will attempt to produce multiple design possibilities following the parameters as guidelines. A concept artist mainly works with concepts; hence, it is crucial to display ideas through their designs. A good 
character will always have a distinguishing feature that helps define their personality or appearance and the distinctiveness can make a character interesting and engaging.

\section{Thumbnails}

Thumbnails and sketches consist of quick drawings commonly used to practice. It is though that sketches is a tool to transmit clear ideas. Occasionally level of detail of sketches or draft often applied and accepted the context of the industry, as long as the main ideas depict a clear information. It is important to have a clear design, where core elements demonstrated. Designers and creative directors can determine whether the concept will work in the film by analysing the sketches.

This stage allows for an overview of the design direction, which eliminates miscommunication between pre-production, production and the client. Character designers must be able to translate ideas quickly and precisely, and the quality of the artwork is not the primary goal at this stage. Design variations with many options have to be produced with in parameter without taking too much time to complete. The final sketch will be a creation of textual and visual concepts gathered throughout the process.

\section{Jungian Archetype}

In ancient Greek, the term "archetype" meant "original pattern." Archetypes are a universal concept that can be particularly useful as a guiding principle for designers who want to precisely identify their character features. In his theory of the human psyche, Jung introduced the idea of archetype (Kendra, 2020). Jungian archetype identified 12 universal, mythic characters archetypes that reside within our collective unconscious which is; The Innocent, Everyman, Hero, Outlaw, Explorer, Creator, Ruler, Magician, Lover, Caregiver, Jester, and Sage.

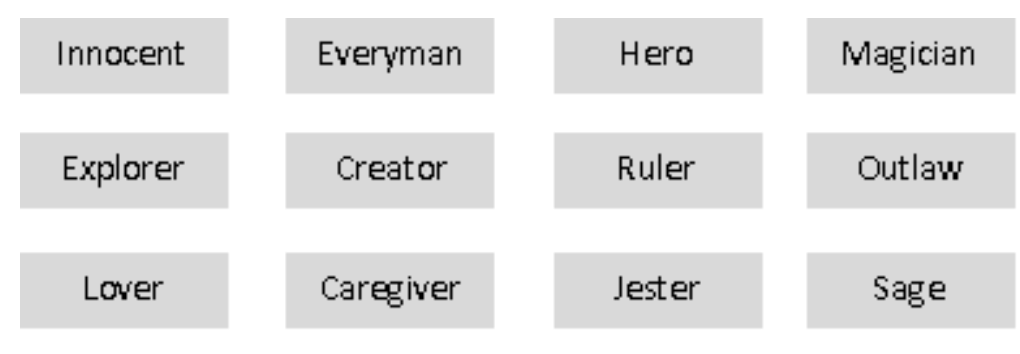

Figure $1: 12$ universal archetype

Figure 1 explains the examples archetypes that reflect the personality of the character and serves to align personality type with specific personas. It is crucial to give a character human feelings and emotions to boost the design's credibility, while designing character's psychological elements.

\section{The Importance of Silhouette}

Another important aspect of physical character design is the silhouette; it helps distinguish characters from one another and from their surroundings, allowing the artist to effectively measure the character's degree of differentiation. When it is necessary to create many 
variations of a concept, silhouette thumbnails are one of the most useful and productive methods of design.

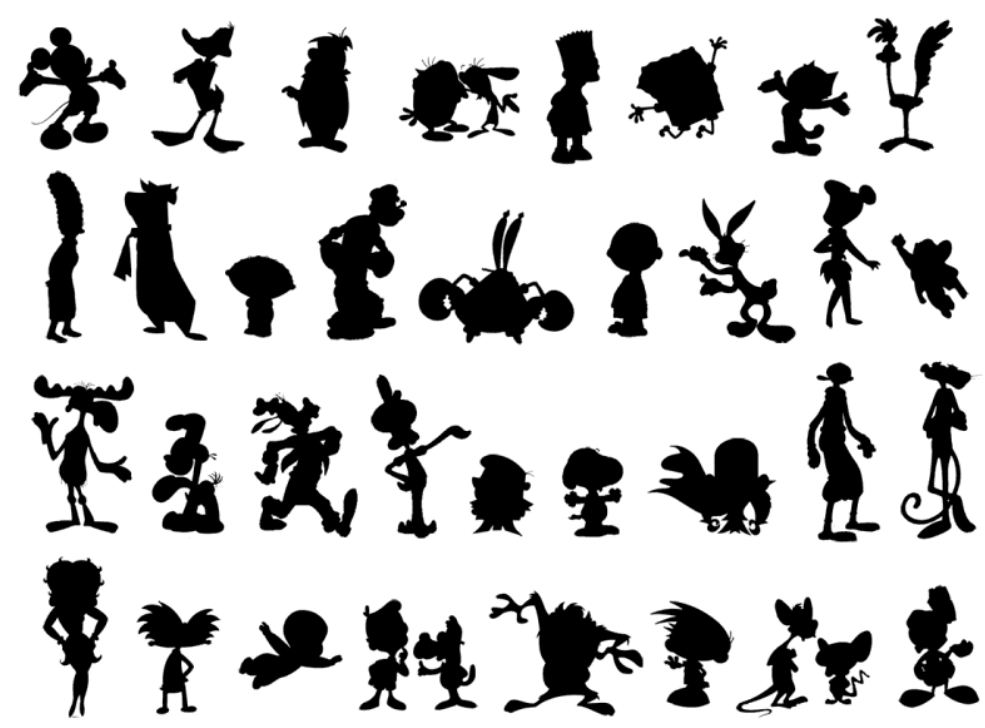

Figure 2: Unique silhouette in global animated content (Characterdesignreference.com)

In Figure 2, shows the use of effective silhouette to identify character's shape, size and body mass for initial development build-up. Often Corriero (2011) argues, the particular method were not applied by all artist and it's certainly not a necessity to design a character purely based of a silhouette shape. The silhouette is necessary further character development process, however not all designers subconsciously focus on shapes and designs; it does not make any distinction impact on the viewer.

\section{Defining Physical Attribute}

The process of adding the appropriate details to the character to make it convincing by adding physical attributes relate to the physicality of the character is referred to as visual attributes. Clothing, facial type, body type, patterns, textures, and other visual representation aspects will be decided in tandem with the character archetype. Physical characteristics are important when designing characters because the audience must have a clear understanding of what the character represents at a glance. It can be in form of built characteristics, height, complexion, or hair. A common way to tackle this is to design the character with exaggerated physical features. Thus, an animated character design must be focused more on creating a look for a character that reflects character personality rather than character realism.

\section{Rendering}

\section{Finalization}

The following stage consists of the process of refining the sketches that were generated during the concept stage. The sketches are then reduced to a possible design solution that incorporates technical limitations. The best sketches will be selected and proceed to finalization. The sketches are therefore polished and refined to be as close to the final ideas as possible. 


\section{Colour}

Colour can represent mood, personality and can be used to convey the emotional and psychological weight of the characters. If colour psychology is not implemented throughout the design process, a character will often seem misrepresented and inconceivable. A good colour sense is the foundation of a good character. Choosing suitable colour tones as the foundation for characters will result in a variety of outcomes. It all depends on the value, story, and message conveyed by the designed character. It is insufficient to create a character through the use of vibrant and bombastic colours. Thus, the combination of colour tones that are aligned with the background stories is more important.

\section{Detailing}

Rendering refers to the action of depicting or representing an idea graphically. A good quality depiction by designers is expected during this stage. The designers thus begin to give the best sketches details and colour as the artwork will be used for another department along the design pipeline. The final design will be revised by the creative directors before the final approval is obtained in accordance with project parameters and technical constraints.

\section{Technical Consideration}

A good designer should be aware of technical limitations and always in check with the technical directors. Limitations such as clothing parameters, rigging capabilities, and shape restriction from the technical department must be considered to avoid incompatibility of design in the final production. However, it is not mandatory for the character designer to comply with the technical requirements. Most of the time, a character design will be tested to its maximum potential and then tuned to meet the project's capabilities. It is agreed that the prime objective of character design is to impress and to inspire.

\section{Suspension of Disbelief}

Development of characters in animation positions a unique viewpoint on the willing suspension of disbelief. The design must be able to explain the context of the content and assist the audience in comprehending and sympathizing, visualizing, understanding, comprehending, and, most importantly to make the character design more believable. The concept of 'suspension of disbelief' is defined as an audience to see the character as a believable context referring to (Oxford Reference, n.d.) where a logical representation of unreal work or fiction, as a function of enjoyment. Bates (1994) agrees where often animators have sought to create believable characters in other hand provides and create an illusion of life, where enabling audience to experience suspension of disbelieve. However other instruments also support the concept. In this sense, Hooks (2011) supported mostly audience accepted a fictitious reality that the story's given premises to identify the characters, such as in reality that Superman do not fly, but fly in the screen. Therefore, an application of successful character design in animation required to create audience willing suspension of disbelief. This means that what they are seeing a character is a fictitious reality, but they are pretending to be unaware of this.

\section{Discussion of Findings}

The process helped to achieve eligible results in determining the suitable process in Nusantara-inspired character design. The proposed method proves to be well-defined in the sense that it facilitated the identification of characters that are effectively coherent and 
consistent. The amalgam of western approach among producers to an entire Southeast Asia runs the risk of confusion, thus impact of the audience culture in the region. The proposed method essentially enables the designer to estimate how far they are from obtaining the desired result when designing Nusantara-inspired characters. Abdullah \& Abdullah (2020) also argue that the use of cultural representation is becoming more evident in contemporary animation and has developed its own circle of enthusiasts. It is important that the ideal character design correlates to the plot and setting of the content. Character creation is often prioritized before other elements are produced or supplemented in animated feature films. The process of creating characters is inherently a process of embodying and visualizing ideas and concepts. Every decision made by the artists alters the set of possible character design solutions and simultaneously display the issues involved in the decision-making process. artists must be aware of the different paths that the process can take in order to produce better solutions.

\section{Conclusion}

The answer towards a good designed animated character with strong embodiment qualities of Nusantara representation and avoiding creating a character that imbued with many traits in a single character. This paper has recommended a model, a map to guide future efforts to highlight and elevate global understanding of Nusantara - inspired content. With a population of 655 million in Southeast Asia, having a historic culture is an opportunity of digital economy in creative content industry with development of such characters into digital contents, and flourish for economy opportunities for artists and designer alike. A balance between characters and characteristics is the key to accurately recognize what the Nusantara is core essence. The spotlight on Nusantara-inspired content of Southeast Asian will offer more opportunities and potentials in mainstream media. It is still initial, and content producers should aware that Southeast Asian cultures are not interchangeable and have a distinct persona especially within the Nusantara region. A cultural representation in Nusantarainspired character must be clustered into a specific theme reflected in its characteristics, background, and rich of its architecture. The idea of portraying eclecticism in character design on a purpose to amuse the whole Southeast Asia audience is just obvious escapism. A monolith idealism of Nusantara-inspired character traits will appear if we truly appreciate the correlation between the textual and visual narrative of its ancient folklore.

\section{Contextual and Theoretical Contribution}

The most important ideas that have been discussing in this article including the fine process of character development. There is also the importance of multi-faceted theoretical background of approach in the development of character and contents. This is where the fundamental theory; suspension of disbelief, as well as Jungian Architype, come into play for developers, as these components were crucial theoretical aspects and were required to develop a physical Nusantara-inspired content. The success of content building and creation of content based on to facade, but it also required multi-layers of elements of comprehending and sympathizing the need of theoretical background of certain cultures, to create the content successful and finally, characters act believable on the stage. Thus, in the end, the aesthetic outcomes were preferred by the audience, and production companies would prefer cheaper processes in benefits for commercial purposes. Somehow, the theoretical background was of utmost crucial to established, where it certainly helps the purpose the idea of portraying true, and effective character design. 


\section{Acknowledgement}

This research is supported financially by Ministry of Higher Education, Fundamental Research grants F03/FRGS/2038/2020 and researchers wish to thank Faculty of Applied \& Creative Arts and Kromosomlab Sdn. Bhd for fully support the implementation of the projects.

\section{Reference}

Abdullah, A. M., \& Abdullah, N. (2020). An Initial Attempt: A Synthesis of Cultural Adaptation and Representation in Animation. International Journal of Academic Research in Business and Social Sciences, 10(12), 546-557.

Arshad, M. R., Yoon, K. H., \& Manaf, A. A. (2018). Character Pleasantness in Malaysian Animated Cartoon Characters. SHS Web of Conferences, 53, 02004. https://doi.org/10.1051/shsconf/20185302004

Bates, J. (1994). The role of emotion in believable agents. Communication of ACM, 37(7).

Bowring, P. (2018). Empire of the Winds: The Global Role of Asia's Great Archipelago (Paperback). Bloomsbury.

Corriero, M. (2011). Character and Creature Design Notes. http://characterdesignnotes.blogspot.com/2011/03/use-of-silhouettes-in-conceptdesign.html

Ekström, H. (2013). How Can a Character's Personality be Conveyed Visually, through Shape. Gotland University.

Giri, N., \& Stolterman, E. (2020). Pixel perfect: Fashion styling in virtual character design process. Lecture Notes in Computer Science (Including Subseries Lecture Notes in Artificial Intelligence and Lecture Notes in Bioinformatics), 12211 LNCS. https://doi.org/10.1007/978-3-030-50164-8_5

Hall, D., \& Estrada, L. C. (2021). Raya and the Last Dragon (2021). In High on Films. Walt Disney Pictures.

https://www.facebook.com/HighonFilmsOfficial/posts/3334818866623517

Hamzah, F., \& Manaf, A. (2020). excerpt-MITOS KOSMOLOGI NUSANTARA.pdf (p. 150). UNIMAS Publisher. http://www.publisher.unimas.my/life-in-publisher/books-online

Hooks, E. (2011, June 10). The Willing Suspension of Disbelief / Animation World Network. Animation World Network. https://www.awn.com/blog/willing-suspension-disbelief

Kendra, C. (2020). The 4 Major Jungian Archetypes. Verywellmind. https://www.verywellmind.com/what-are-jungs-4-major-archetypes-2795439

Lent, A. J. (2004). The Sleeper Status of Southeast Asian Animation. Malaysian Journal of Communication, 9(17), 183-199.

Lim, N. (2016). Cultural differences in emotion: differences in emotional arousal level between the East and the West. Integrative Medicine Research, 5(2), 105-109. https://doi.org/10.1016/j.imr.2016.03.004

Lioi, J. (2009). Framework for development of schemata in character design for computre animation. In Ohio State University (Vol. 39, Issue 5). Ohio State University.

Oxford Reference. (n.d.). Suspension of disbelief - Oxford Reference. Retrieved May 31, 2021, from https://www.oxfordreference.com/view/10.1093/oi/authority.20110803100544310

Ramos, J., Filho, S., De Oliveira, A., Franco, R., Gilvan, J., Maia, R., Ao, J., Da, R., Roger, L., Mem', M., Machado, M., Anacleto, N., Junior, C., \& Jos', J. (2016). Character Design: a new Process and its Application in a Trading Card Game IS RPG View project RPG analyses View project Character Design: a new Process and its Application in a Trading 
INTERNATIONAL JOURNAL OF ACADEMIC RESEARCH IN BUSINESS AND SOCIAL SCIENCES

Vol. 11, No. 7, 2021, E-ISSN: 2222-6990 @ 2021 HRMARS

Card Game. October 2017. http://www.gamasutra.com/

Seegmiller, D. (2007). Digital Character Painting Using Photoshop CS3 (Graphics Series) (2nd ed.). Charles River Media. 